Article

\title{
Measuring Urban Resilience to Climate Change in Three Chinese Cities
}

\author{
Mingshun Zhang ${ }^{1, *(\mathbb{D})}$, Yaguang Yang ${ }^{1}$, Huanhuan $\mathrm{Li}^{1}$ and Meine Pieter van Dijk ${ }^{2,3}$ \\ 1 Beijing Climate Change Response Research and Education Centre, Beijing University of Civil Engineering \\ and Architecture, Beijing 100044, China; 2108300219005@stu.bucea.edu.cn (Y.Y.); lhh805825@163.com (H.L.) \\ 2 Maastricht School of Management (MSM), 6229 EP Maastricht, The Netherlands; mpvandijk@iss.nl \\ 3 International Institute of Social Studies (ISS), Erasmus University Rotterdam, \\ 3062 PA Rotterdam, The Netherlands \\ * Correspondence: zhangmingshun@bucea.edu.cn
}

Received: 17 October 2020; Accepted: 20 November 2020; Published: 22 November 2020

check for updates

\begin{abstract}
Building an urban resilience index results in developing an increasingly popular tool for monitoring progress towards climate-proof cities. This paper develops an urban resilience index in the context of urban China, which helps planners and policy-makers at city level to identify whether urban development is leading to more resilience. The urban resilience index (URI) suggested in this research uses data on 24 indicators distributed over six URI component indices. While no measure of such a complex phenomenon can be perfect, the URI proved to be effective, useful and robust. Our findings show that the URI ensures access to integrated information on urban resilience to climate change. It allows comparisons of cities in a systematic and quantitative way, and enables identification of strong and weak points related to urban resilience. The URI provides tangible measures of not only overall measures of urban resilience to climate change, but also urban resilience components and related indicators. Therefore, it could meet a wide range of policy and research needs. URI is a helpful tool for urban decision-makers and urban planners to quantify goals, measure progress, benchmark performance, and identify priorities for achieving high urban resilience to climate change.
\end{abstract}

Keywords: urban resilience; resilience assessment; hazards management; climate change; urban governance

\section{Introduction}

In many cities, climate change and urban resilience are high on the political agenda. For climateproof cities, the focus is often limited to the reduction of Green House Gas (GHG) emissions and introducing resilience. From a governance point of view (defined as involving stakeholders), the potential victims may be involved in urban management in resilient cities [1], while in the sponge city concept, the idea is to involve the private sector, although this has not happened most of the times in China, where this concept has its origins [2]. The key question is whether cities can adapt to the new situation. This is called the absorptive capacity of a city, or its resilience. Building an urban resilience index results in an increasingly popular tool for monitoring progress towards climate-proof cities. While urban resilience assessment developers tend to use a considerable number of indicators to take all dimensions of urban resilience into account, urban resilience assessment users are eager to use simple, practical, and effective indicators for tackling the crucial elements of urban resilience. To bridge the gap, there is a need to develop an urban resilience index based on as small as possible a number of indicators, however, without compromising the underlying complexity of the concept of urban resilience to climate change. 
There is no agreed method on how to measure urban resilience to climate change. The most common way to overcome this constraint and to make the concept of resilience operational is to use indicators. The most popular example is the World Risk Index (WRI) that is an approach to assess global exposure, vulnerability and risk patterns based on national scale resolution data [3]. WRI is based on the analysis of 28 indicators assessing global risk pattern, and those 28 indicators are closely linked to the 17 UN SDGs [4]. Since WRI is on a global scale and there is a need to develop similar WRI within local context [5], Queiroz [6] adapted WRI into the Brazil National Scale by using different databases and indicators that are developed within the local context. After having defined the purpose of a resilience assessment, indicating variables or indicator components need to be selected and aggregated for the creation of a city-level indicator. The purpose of the assessment defines the temporal and spatial scale of the indicator components as well as the aggregation level. Manyena [7] analyzed the origin and development of the concept of resilience, and re-examined the concept of disaster resilience on whether it is a pattern or an outcome, a process or a result, and its relationship with vulnerability. Manyena discussed and summarized the guiding role of resilience thinking in response to disasters. Cutter et al. [8] developed a framework for resilience assessment based on a literature review. The aim was to improve the comparative assessment of disaster resilience at the local or community level. Using this model, a community resilience assessment index system was constructed which contains six dimensions (ecological, social, economic, infrastructure, institutions and community) and 30 sub-indexes. Simpson [9] proposed a community resilience index model in which the Disaster Resilience Index (DRI) is developed from the ratio of community readiness and community vulnerability. Community readiness and community vulnerability are developed based on a series of spatial and non-spatial indicators of community resources, including material, economic, social, cultural and ecological aspects. Based on the definition of urban resilience from the United Nations International Strategy for Disaster Reduction (UNISDR) and also Simpson's community resilience assessment method, Kusumastuti et al. [10] developed an urban resilience assessment framework in response to natural disaster. Blackmored and Plant [11] discussed the measures of enhancing sustainability of urban water systems from the perspective of risk and resilience. Suárez et al. [12] defined urban resilience from a socio-ecological perspective and developed a methodological framework for measuring urban resilience as well as defining the urban resilience index. Joerin et al. [13] constructed a Climate Disaster Resilience Index (CDRI) model containing five dimensions (economy, institutions, nature, material and society), and used this model to assess the urban resilience of Chennai, India. CDRI includes five dimensions, 25 parameters and 125 variables. Kim et al. [14] considered urban resilience as an important measure to adapt to climate change and proposed a conceptual framework for urban resilience analysis in the context of climate change.

Various international organizations have launched international cooperation plans on the build-up of urban resilience. The two most representative international cooperation programs are the "Making Cities Resilient" campaign from the United Nations International Strategy for Disaster Reduction (UNISDR) and the Rockefeller Foundation's "100 Resilient Cities" plan. The former aims to enhance urban resilience in response to disasters and risks. It defines urban resilience as the ability of cities to recover, adapt and sustainably develop under all kinds of impacts [15]. The Rockefeller Foundation partnered with a consultancy firm, ARUP, and developed the City Resilience Framework (CRF) and City Resilience Index [16]. City resilience consists of four elements. First, a resilient city looks after the health and well-being of people living and working in the city. Second, the economy and society enable people to live peacefully, and act collectively. Man-made infrastructure and natural systems can provide critical services, protect and connect people. Finally, leadership and strategy are needed for informed, inclusive and integrated decision-making. There are 12 goals, three per element. They can guide cities in improving its functions to become resilient. The 12 goals are supported by 52 indicators. They were developed to integrate the qualities of resilient systems. The seven qualities of resilient systems are being reflective, robust, redundant, flexible, resourceful, integrated and inclusive. Reflective systems 
reflect on past experiences. They use these experiences to adapt and, for example, to adjust standards and norms to be able to deal with the consequences of the disaster.

The current urban resilience assessment frameworks have few indicators that can measure the resilience against non-specific risks, instead, they often emphasize the resilience against a specific type of disturbance such as natural disasters (e.g., earthquakes, floods, etc.) [10,17]. However, the high uncertainty caused by climate change means that resilience must be established for wider disturbances [18]. Furthermore, the existing resilience assessment indicators are mainly focusing on a single part of the urban system such as energy [19], water supply [20] or urban drainage system [21], etc., and lack of an understanding of the comprehensive urban resilience. Three challenges remain in assessing urban resilience. The first one is to assess an integrated urban resilience instead of assessing urban resilience to a specific hazard. Measuring resilience to a specific hazard or risk is relatively easy. However, assessing comprehensive resilience is much more complex. The second challenge is the quantification. Existing resilience assessments are mainly applying qualitative approaches, which leads to limited acceptance of the assessment results. The third issue is to assess urban resilience by using a reasonable number of indicators. In many cases, large numbers of indicators are applied and thus, much information and high costs of data collection are needed.

Resilience is multidimensional as well as place-, scale- and time-specific, which requires a comprehensive approach for measuring and analyzing. In this regard, composite indicators or indexes are preferred [22]. The objective of this research is to develop an integrated urban resilience assessment tool for Chinese cities, based on a reasonable number of indicators and helping policy-makers at the city and community levels to gain insight in urban resilience to climate change. Specifically, this research addresses the following issues:

(1) Developing a conceptual urban resilience assessment framework within the local context of urban China.

(2) Selecting indicators by using the framework developed by this research and reducing numbers of indicators to a reasonable scale for ensuring effective assessment of urban resilience to climate change.

(3) Creating an integrated urban resilience index (URI) by weighting the selected indicators and testing the URI in three Chinese cities: Beijing, Chongqing and Yiwu.

\section{Materials and Methods}

\subsection{Development of a Conceptual Urban Resilience Assessment Framework}

For developing a conceptual assessment framework, it is crucial to understand and define urban resilience to climate change. The poor resilience affects the people living and working in cities. The immediate response to a crisis tends to be: try to get a better understanding by measuring phenomena, introduce more regulation and go for a better planning system. Introducing new rules is an understandable first reaction. However, urban management requires a localized understanding and targeted response in the face of all kinds of initiatives by communities and companies to deal with the crisis. This shows the necessity of giving stakeholders a role in urban governance. Benefitting from a crisis through adaptive rather than top-down governance structures has been recommended [23]. Van Dijk gives examples of adaptive governance. The reactions define the city after a pandemic or other crisis and require more resilient organizations, economies, communities and people. The different phases and levels of resilience are certainly interlinked. IPCC defined resilience as the capacity of social, economic and environmental systems to cope with a hazardous event or trend or disturbance, responding or reorganizing in ways that maintain their essential function, identity and structure, while also maintaining the capacity for adaptation, learning, and transformation [24].

In order to build a conceptual framework of urban resilience in the context of climate change, this paper analyzes and integrates the various perspectives on urban resilience from the relevant literature. The key components of urban resilience mentioned in most literature include social, economic, 
natural/ecological environment, institutions, and resources/infrastructure, and each component is assessed by several indicators $[8,10,13,14,25,26]$. Different researchers have different interpretations of these economic and natural/ecological environmental components. For example, Kusumastuti et al. [10] consider economic resilience as an adaptive response of individuals or markets to disasters while Cutter et al. [26] consider economic resilience as the economic vitality of a community. Similarly, Razafindrabe et al. [27] propose that ecological resilience is related to the frequency and intensity of disasters while Cutter et al. [26] considers that ecological resilience is related to biodiversity and land utilization. These differences are also due to the scale of the area considered and the objectives of the different studies.

Building on the literature and the above mentioned IPCC definition on resilience, this research proposes a conceptual framework for an urban resilience assessment in the context of climate change, which is presented in Figure 1.

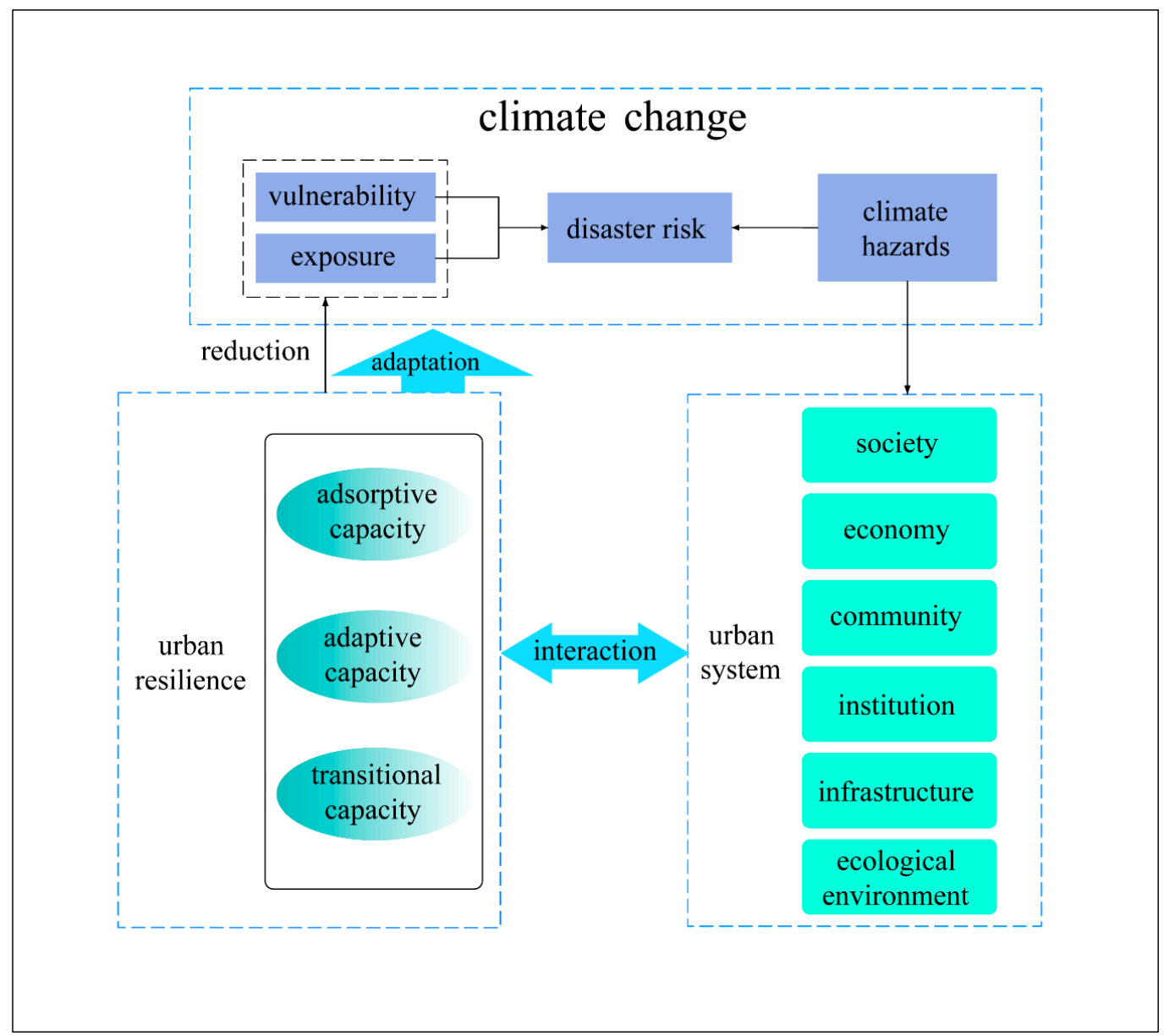

Figure 1. Conceptual framework for assessing urban resilience to climate change.

The framework divides the assessment of urban resilience into 6 dimensions or urban systems: economy, society, community capacity, infrastructure, ecological environment and institutions. These 6 urban systems are interlinked and are the key systems affecting urban abilities to resist, absorb and adapt to disasters and transformation.

Each dimension is divided into several sub-dimensions that can be assessed by a number of statistical indicators (e.g., the social dimension can be further divided into 3 sub-dimensions: demographic characteristics, social preparation and social services). In total, urban resilience to climate change can be assessed by 6 dimensions and 14 sub-dimensions, as presented in Figure 2. 
Urban resilience to climate change is closely related to the social and community aspects. Society and community are organized, disciplined and interrelated social groups. However, whereas society emphasizes the macro level more, the community emphasizes the specific micro level circumstances. At the social level, urban demographic characteristics (age, education level, population density, etc.) are important factors influencing urban vulnerability to cope with climate change. Meanwhile, the adequacy of social preparation and the level of social services determine urban responsiveness and resistance to disasters, and hence whether the city can minimize the impact of disasters. At the community level, the focus is on the role of a community environment with collective identity and mutual support in response to disasters. A united and cohesive community structure and active community participations help to improve a city's learning and organizing capabilities in response to disasters. In addition, a prior experience of a disaster would be valuable, since this will affect people's ability to react and cope.

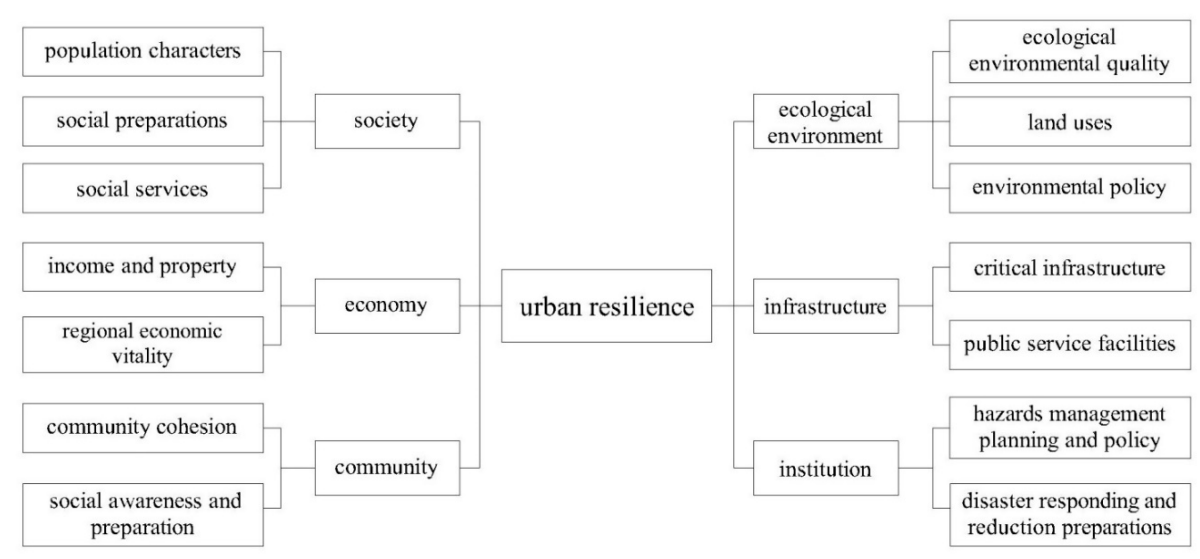

Figure 2. Dimensions of the urban resilience assessment.

The economic dimension reflects citizens' income as well as the extent to which they can convert income into savings that can be used during disasters. This is similar to the health and well-being of people as emphasized in the City Resilience Assessment Index (CRI) by the Rockefeller Foundation. The economic dimension also represents other aspects such as the diversity of the city's economy, its flexibility, its ability to attract corporate investment, fund allocation and the ability to allocate emergency funds.

Infrastructure is a vital tangible asset, function and system in order to ensure urban health, safety and wealth. Infrastructure resilience refers to the ability of urban infrastructure in response to and to recover from disasters, such as the ability to secure city infrastructure and lifelines. Yiwen Shao, Jiang $\mathrm{Xu}$, et al. [28] also pointed out the importance of ensuring the operation of lifeline projects and emergency response capabilities in building infrastructure resilience. Energy (electricity and natural gas, etc.), transportation (roads and railways, etc.), communications (Internet, etc.), and water supply and drainage facilities are lifeline systems that maintain the livelihood and production activities of urban residents. At the same time, social (education, health and housing, etc.) infrastructure is also closely related to the livelihood of residents. Indicators of these areas can be used to measure the resilience level of urban infrastructure to climate disasters.

The institutional dimension serves to measure local governance capacity to deal with disasters, including whether they have disaster management plans and policies, whether they can ensure the availability of early warning systems and the ability to spread disaster information in a timely and effective manner. In addition, whether the local governments can communicate and cooperate with other stakeholders (non-governmental organizations, private organizations or other regional government organizations) during disasters is also crucial for the functioning of the entire system.

The dimension of natural environment reflects the vulnerability and sustainability of various ecosystems (air quality, green coverage, heat waves and general overheating of the cities due to 
the energy disbalance of an urban system that are proven to greatly affect the human health and comfort, but also to damage built systems and drive the increased emissions from the building sector). Understanding the urban eco-environmental attributes is critical to determine whether the city can absorb the potential impact of a disaster. Meanwhile, environmental policies are also important to enhance the resilience of the urban ecological environment.

\subsection{Selection of Urban Resilience Assessment Indicators}

Based on the 6 dimensions of urban resilience as shown in Figure 2 and a careful review of the literature, a database of urban resilience indicators has been established, which includes 127 single indicators. Data availability does not permit us to use all 127 indicators. In order to reduce the number of indicators, we applied a pre-coded questionnaire to 36 specialists from national and local levels for selecting indicators from the database by using the following six principles. Among the 36 specialists, 18 are from national level, and 18 are from the three selected cities of Beijing, Chongqing and Yiwu.

In total, 24 indicators have passed the following four principles test.

(1) Selecting indicators that are the most frequently mentioned in the existing literatures $[1,3-6,9-14,16,20]$ and are included in the local existing statistical system.

(2) Deleting highly repetitive indicators.

(3) Localizing selected indicators within local context.

(4) Policy relevance, scientific soundness and measurability.

\subsection{Weighting Indicators}

A frequently mentioned issue in developing an integrated assessment index is how the index's inputs should be weighted. In most of the international index development programs, nominally, all inputs from individual indicators receive equal weight. No indicator gets more weight than any other. Results of weighting indicators in most international index development are not acceptable for two reasons. One is that weights identified by different experts from different countries are likely to differ significantly. This is because situations are different from one country to another. Another reason for getting poor results is probably that a complicated issue, such as resilience, leads to confusion among different experts. Weights are the measures of importance. The important factors that allow us to adopt a weighting approach for the aggregation of indicators are twofold. One is for the cross-city comparisons. Most Chinese cities are quite similar in terms of economic growth, social progress, institutional ability and environmental pressures. Therefore, a scientifically acceptable determination of the weights should be achieved. Secondly, we used the Analytical Hierarchy Process (AHP) method [29], together with consultation of the 36 experts mentioned in the Section 2.2. One of the main advantages of the AHP is that it allows experts to compare two factors by using the same criteria and scoring rules. As the identification with the same criteria and scoring rule is quite simple, statistical results can easily be obtained at an acceptable level. Table 1 shows the weights of each of the 6 dimensions and each of the 24 indicators that are calculated by AHP, together with expert consultations.

As shown in Table 1, among the 6 dimensions, institutions, infrastructure, ecological environment and economic resilience have more weights and are the key factors affecting urban resilience in responding to climate disasters. Among the 24 indicators, medical insurance coverage, unemployment insurance coverage, urban green coverage and disposable income per capita have more weight and are the most important factors affecting urban resilience.

For the 24 indicators, data is available from local statistics except two institutional indicators of emergency response capacity and integrated governance capacity. In this research, the emergency response capacity in each of the three cities is evaluated by the above mentioned 36 specialists. The evaluation is based on reviewing relevant documents, local policy papers, strategies and action plans for an emergency response, evaluating the availability of relevant resources for responding to 
emergencies, the damages caused by the past emergency and the results of local government dealing with emergency cases in the past.

Integrated governance capacity is one of the most important factors of urban resilience. It can be evaluated by two aspects. One is the governance process, and the other is the public response to the governance, which is the progress made due to the governance structure. Good governances are characterized by the presence of participatory processes and a high public satisfaction with the institutions. In this research, citizens' satisfaction with their city and participation has been used for evaluating governance capacity. By expert consultation, we eventually selected citizens' satisfaction with their city as the indicator for urban governance capacity. There are two reasons for this choice. One is the high correlation between citizens' satisfaction with their city and stakeholder participation. The other is that it is technically difficult to quantitatively evaluate public participation. From the questionnaire, we learned that most of the interviewed experts found it difficult to answer the question on their involvement in urban management. Therefore, we had to select 20 specific urban programs in each of the three cities for helping them to answer the questions on availability of information, building consensus, and public participation. The 20 specific urban programs are affordable housing, sewage, public transport, education, social welfare, drinking water, employment, transparent and useful media, open local government, democratic local government, water supply, electricity supply, road, security and safety, air quality, waste management, income support programs, participatory decision-making, efficient local government and accountable local government.

Integrated governance capacity is the only indicator whose score is based on surveys among the population. Therefore, it is impossible to get the scores from before 2018 when our fieldwork was conducted. For getting an historical overall insight of the URI, the scores for integrated governance capacity from 2010 to 2017 were estimated by the 36 experts mentioned in Section 2.2 through historical reviews of relevant documents, reports and/or progress made related to the above mentioned 20 urban programs.

\subsection{Calculating URI}

The URI advanced in this research is the weighted sum of the six components and each component is the weighted sum of several individual indicators. The formula for calculating URI is as follows:

$$
\begin{gathered}
U R I=\sum_{i=1}^{6} w_{i} D_{i} \\
D_{i}=\sum_{j=1}^{n_{i}} u_{i j} Y_{i j}
\end{gathered}
$$

where URI is urban resilience index; $D_{i}$ is resilience component index; $Y_{i j}$ is standardized value of each individual indicator; $w_{i}$ is weight of each dimension and $u_{i j}$ is weight of each individual indicator.

\subsection{Case Study Cities}

This research targets three cities: Beijing, Chongqing and Yiwu for testing the URI. In both Beijing and Chongqing, the municipalities fall directly under the central government. These are megacities with large population and areas. Beijing is the capital of China and is located in eastern China, while Chongqing is the largest city in western China. Both cities have monsoonal climate and the temperature and precipitation change drastically in the winter and the summer, and hence they are easily affected by climate change. Yiwu, located in the eastern Zhejiang Province, is a small and medium-sized city and a city where the private sector plays an important role. Yiwu is also one of the four cities in China targeted by the Rockefeller Foundation's "Global 100 Resilience City" program. The reason for choosing small- and medium-sized cities is that in such cities, it is easier to make adjustments and changes. By comparing the differences in the resilience levels of megacities and small- 
and medium-sized cities, the big cities also provide a reference point for building resilience in smaller cities. The following Table 2 presents profiles of the three case study cities. 
Table 1. URI (urban resilience index) components, indicators and their weights.

\begin{tabular}{|c|c|c|c|c|}
\hline Components & Weight & $\begin{array}{c}\text { Indicators } \\
\text { (+: Positive Indicator; } \\
-: \text { Negative Indicator) }\end{array}$ & Weight & Integrated Weight \\
\hline \multirow{7}{*}{ Society } & \multirow{7}{*}{0.056} & Percentage of population below 14 years old (-) & 0.065 & 0.004 \\
\hline & & Percentage of population above 65 years old (-) & 0.199 & 0.011 \\
\hline & & Percentage of population with high education $(+)$ & 0.139 & 0.008 \\
\hline & & Urban population density $(-)$ & 0.136 & 0.008 \\
\hline & & Number of mobile phones per 10,000 persons $(+)$ & 0.049 & 0.003 \\
\hline & & Health technicians per 10,000 population $(+)$ & 0.254 & 0.014 \\
\hline & & Proportion of population receiving social assistance (-) & 0.158 & 0.009 \\
\hline \multirow{4}{*}{ Economy } & \multirow{4}{*}{0.197} & Urban citizen's disposable income (+) & 0.404 & 0.080 \\
\hline & & Registered urban unemployment rate $(-)$ & 0.278 & 0.055 \\
\hline & & Tertiary sector of the economy sharing in GDP $(+)$ & 0.112 & 0.022 \\
\hline & & Energy consumption per 10,000 GDP $(-)$ & 0.207 & 0.041 \\
\hline \multirow{2}{*}{ Community } & \multirow{2}{*}{0.061} & Proportion of disaster prevention and mitigation communities $(+)$ & 0.606 & 0.037 \\
\hline & & Community service agency coverage $(+)$ & 0.394 & 0.024 \\
\hline \multirow{6}{*}{ Infrastructure } & \multirow{6}{*}{0.230} & Availability and supply capacity of water resources $(+)$ & 0.267 & 0.061 \\
\hline & & Rate of household waste treatment $(+)$ & 0.264 & 0.061 \\
\hline & & Per capita urban road area $(+)$ & 0.105 & 0.024 \\
\hline & & Public transport for every 10,000 people $(+)$ & 0.062 & 0.014 \\
\hline & & Road freight density $(+)$ & 0.051 & 0.012 \\
\hline & & Coverage of medical and health institutions $(+)$ & 0.251 & 0.058 \\
\hline \multirow{3}{*}{ Ecological environment } & \multirow{3}{*}{0.209} & Proportion of days with good air quality $(+)$ & 0.285 & 0.060 \\
\hline & & Urban green coverage $(+)$ & 0.440 & 0.092 \\
\hline & & Comprehensive reusing rate of general industrial wastes $(+)$ & 0.274 & 0.057 \\
\hline \multirow[b]{2}{*}{ Institutions } & \multirow{2}{*}{0.246} & Emergency response capacity (+) & 0.439 & 0.108 \\
\hline & & Integrated governance capacity $(+)$ & 0.561 & 0.138 \\
\hline
\end{tabular}


Table 2. Profiles of the three case study cities.

\begin{tabular}{|c|c|c|c|}
\hline & Beijing & Chongqing & Yiwu \\
\hline Geographical and climatic features & $\begin{array}{l}\text { cold area, } 17,000 \mathrm{~km}^{2} \text {, annual average } \\
11.8^{\circ} \mathrm{C} \text {, annual precipitation } 650 \mathrm{~mm}\end{array}$ & $\begin{array}{c}\text { hot summer and cold winter, } 82,000 \mathrm{~km}^{2} \\
\text { annual average } 18^{\circ} \mathrm{C} \text {, annual } \\
\text { precipitation } 1100 \mathrm{~mm}\end{array}$ & $\begin{array}{c}\text { hot summer and cold winter, } 1100 \mathrm{~km}^{2}, \\
\text { annual average } 17^{\circ} \mathrm{C}, \\
\text { annual precipitation } 1600 \mathrm{~mm}\end{array}$ \\
\hline Economy & $\begin{array}{l}\text { GDP in 2019: } 505 \text { billion USD, GDP per } \\
\text { capita: } 23,500 \text { USD }\end{array}$ & $\begin{array}{c}\text { GDP in 2019: } 337 \text { billion USD, GDP per } \\
\text { capita: } 11,049 \text { USD }\end{array}$ & $\begin{array}{l}\text { GDP in 2019: } 20 \text { billion USD, GDP per } \\
\text { capita: } 25,000 \text { USD }\end{array}$ \\
\hline Society & $\begin{array}{c}\text { Population } 21.5 \text { million, total capital per } \\
\text { household } 1.3 \text { million USD }\end{array}$ & $\begin{array}{c}\text { Population } 30.5 \text { million, total capital per } \\
\text { household } 0.4 \text { million USD }\end{array}$ & $\begin{array}{c}\text { Population } 0.8 \text { million, total capital per } \\
\text { household } 0.7 \text { million USD }\end{array}$ \\
\hline
\end{tabular}




\section{Results}

\subsection{Overall URI in the Three Target Cities since 2010}

To achieve high urban resilience to climate change, it is crucial to provide urban managers the essential information and to help them analyze the conditions of urban systems and how to coordinate these urban systems to realize their potential for resilience to climate change in the future. Figure 3 shows that no matter where the three cities are at this moment, they are all moving in the right direction towards higher resilience. Among the three cities, Beijing has been at the highest resilience level since 2010, while Chongqing's URI is the lowest. From 2010 to 2018, the URI has increased by $104.9 \%$ in Chongqing, by $37.7 \%$ in Beijing and by $29.9 \%$ in Yiwu. Urban resilience has risen steadily in both Beijing and Yiwu since 2010, due to the fact that both cities have set up their urban institutions as well as urban action plans to respond to urban climate risks since 2010. Consequently, both cities have set up specific annual budgets and developed a number of potential projects aiming at improving their urban resilience or adaptive capacities. These potential projects cover the urban resilience-related sectors of infrastructures, building of governance capacity, public awareness campaigns, renovation of the old urban areas that are most vulnerable, and these projects are being implemented step by step. Chongqing has not worked on its urban institutional resilience structures before 2011. Therefore, URI was about 0.20 in each of 2010 and 2011. Chongqing, learning from China's eastern developed cities, started to set up its urban institutional resilience in 2011 and, as shown in Figure 3, its URI reached 0.40 in 2012, which was double the score of 2011. After 2012, its URI stabilized and there has been no significant increase since 2012. The main reason is the low climate hazard awareness in Chongqing's decision-making process and in public opinion, since Chongqing, as an inland city, far away from the sea and climate hazards such as storms and typhoons which are not happening often compared to the eastern seaside cities, such as Yiwu. A detailed explanation per city is presented in the following section.

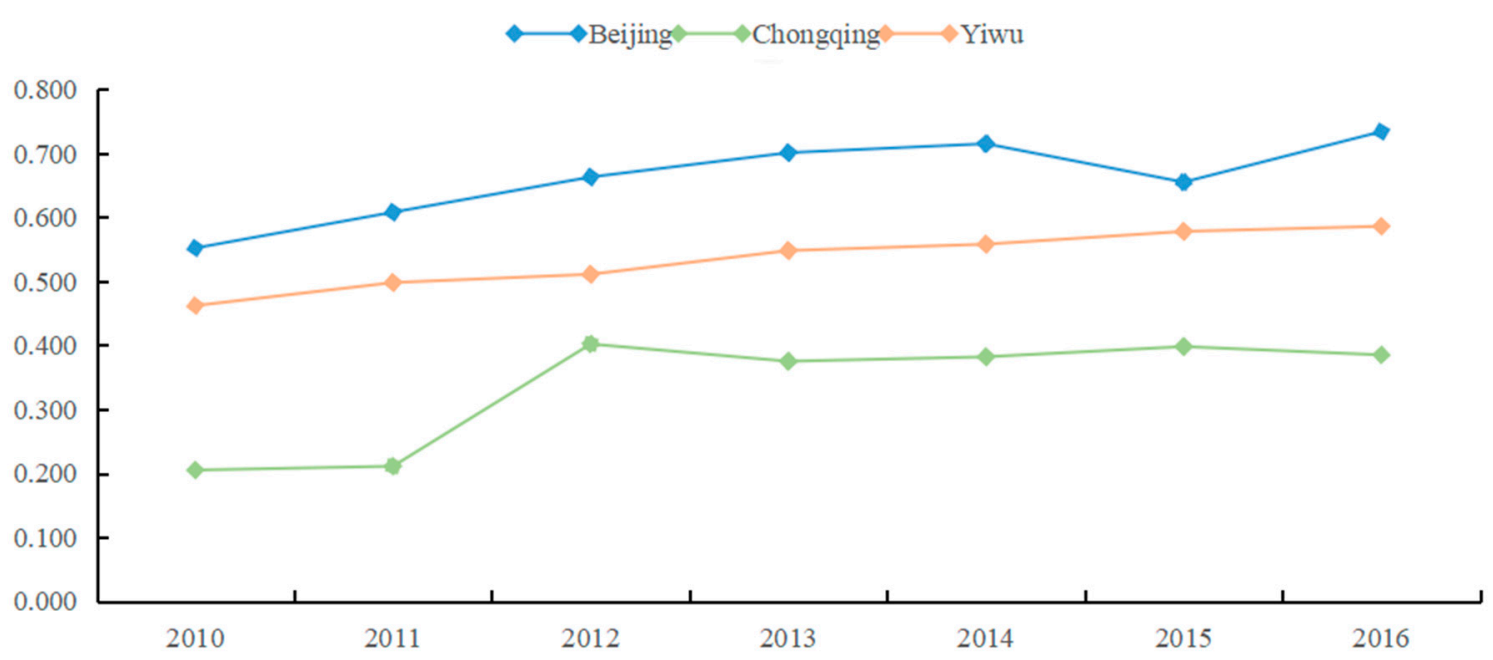

Figure 3. URI in the three target cities since 2010.

\subsection{URI Components in the Three Target Cities}

Each of the six URI components contributes to the overall URI in different ways and thus, it is crucial to identify the main contributors to the URI in each of the three cities. Generally, a component with more weight is more important to the URI. As presented in Table 1, the most important contributor of URI are the institutions, followed by the components of infrastructure, ecological environment and economy. The components of society and community are less important. The following Figure 4 presents the component scores of URI in the three target cities in 2018. 


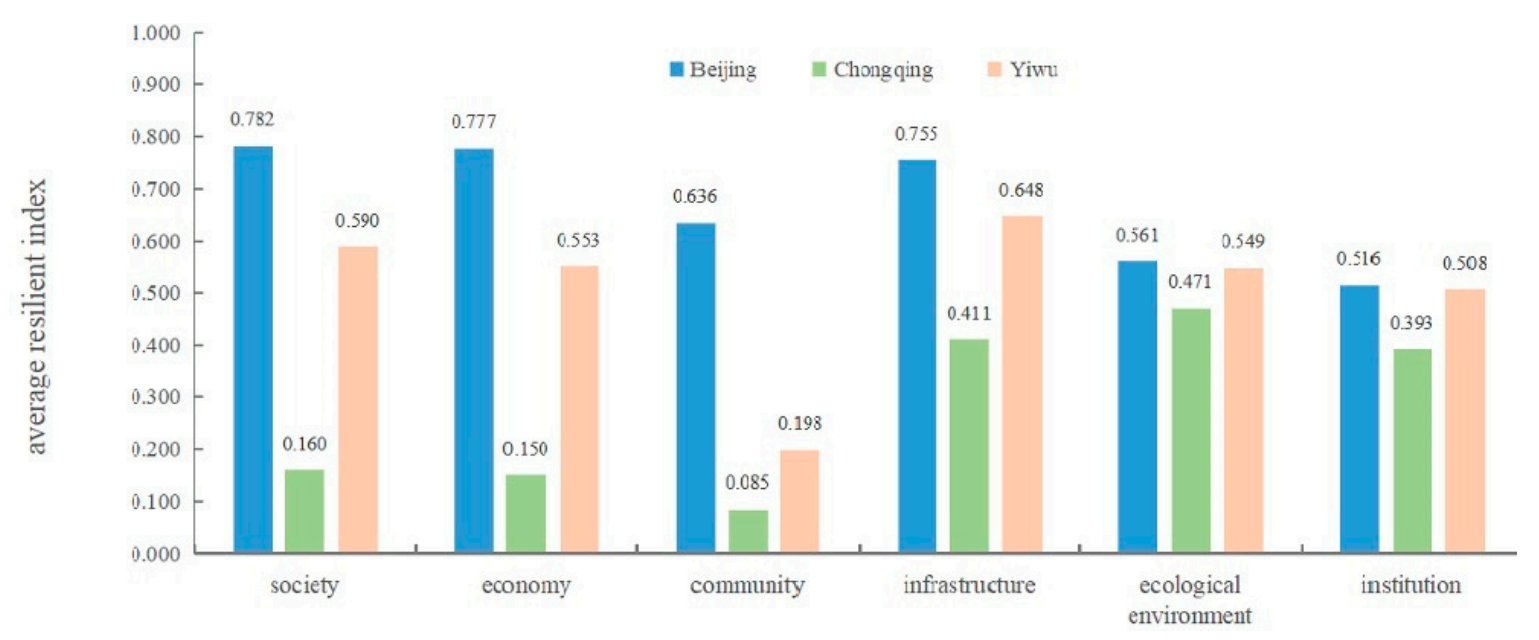

Figure 4. URI components in three target cities in 2018.

As presented in Table 3, main contributors of URI are infrastructure, economy, institutions and ecological environment in Beijing. The main component contributors in Yiwu are quite similar to Beijing, while main component contributors in Chongqing are ecological environment, institutions and infrastructure.

Table 3. Component's contribution to URI by percentage.

\begin{tabular}{ccccccc}
\hline & Society & Economy & Community & Infrastructure & Ecological Environment & Institutions \\
\hline Beijing & $6.7 \%$ & $23.4 \%$ & $5.9 \%$ & $26.6 \%$ & $17.9 \%$ & $19.4 \%$ \\
Chongqing & $2.7 \%$ & $8.9 \%$ & $1.6 \%$ & $28.4 \%$ & $29.5 \%$ & $29.0 \%$ \\
Yiwu & $6.1 \%$ & $20.1 \%$ & $2.2 \%$ & $27.5 \%$ & $21.1 \%$ & $23.0 \%$ \\
\hline
\end{tabular}

By taking into account the general weights and the real assessment results in the three target cities, we concluded that resilient institutions, resilient infrastructure and resilient natural environment are the most important factors for improving urban resilience to climate change. The economy is also important, but it is not the determining factor. Thus, no matter whether a city is rich or poor, its resilience to climate change can be improved by building up efficient governance, enhancing green environment and investing in green infrastructure.

\subsection{Institutional Resilience in the Three Target Cities}

The urban governance capacity is the most important indicator of institutional resilience and its score is based on citizens' satisfaction with 20 issues regarding city performance. The 20 issues are affordable housing, sewage, public transport, education, social welfare, drinking water, employment, transparent and useful media, open local government, democratic local government, water supply, electricity supply, road, security and safety, air quality, waste management, income support programs, participatory decision-making, efficient and accountable local government. The experts interviewed answered the questions related to these 20 issues by scoring between 0 and 100 . For exploring the differences among the three cities, we have grouped the 20 issues by average score which are from less than 40, from 40 to 70, and more than 70. A score less than 40 means dissatisfied; 40-70 means between, and more than 70 means satisfied. The areas which scored less than 40 and more than 70 are presented in Table 4. 
Table 4. Citizens' satisfaction with their city performance (Based on questionnaire in 2018).

\begin{tabular}{cll}
\hline City & & \multicolumn{1}{c}{ Issues Scored Less Than $\mathbf{4 0}$} \\
\hline & & \\
& $(1)$ & affordable housing \\
& $(2)$ & social welfare \\
Beijing & $(3)$ & employment \\
& $(4)$ & transparent media \\
& (5) & participation in decision-making \\
& (6) & air quality
\end{tabular}

Issues Scored More Than 70
(1) education
(2) democratic local government
(3) accountable local government
(4) efficient local government
(5) income support programs
(6) garbage collection and disposal
(7) security and safety (crimes)
(8) electricity supply

$\begin{array}{lll} & (1) \text { affordable housing } \\ & (2) \text { sewage } \\ & (3) \text { public transport } \\ \text { Chongqing } & (4) \text { social welfare } \\ & (5) \text { employment } \\ & (6) \text { participation in decision-making } \\ & (7) \text { income support programs }\end{array}$
(1) education
(2) clean drinking water
(3) democratic local government
(4) accountable local government
(5) efficient local government
(6) garbage collection and disposal
(7) electricity supply

$\begin{array}{lll} & \text { (1) } & \text { sewage } \\ & (2) & \text { public transport } \\ \text { Yiwu } & (3) \text { schools and university } \\ & (4) \text { social welfare } \\ & (5) \text { transparent media } \\ & \text { (6) } & \text { participation in decision-making }\end{array}$
(1) clean drinking water
(2) open local government
(3) democratic local government
(4) accountable local government
(5) efficient local government
(6) income support programs
(7) air quality
(8) electricity supply

Figure 4 indicates that score of integrated urban governance capacity is relatively low compared to the other five URI components, and there is no significant difference of the scores among the three cities. From Table 4, it can be concluded that citizens in the three cities are not very satisfied with the city's governance. Among the 20 issues related to urban performance, citizens in all three cities are not satisfied with social welfare and participation in decision-making. The unsatisfactory issues in Beijing also include affordable housing, employment, transparent media and, in particular, air quality. Citizens in Chongqing are also not satisfied with affordable housing, sewage, public transport, employment and income support programs. Citizens in Yiwu are not satisfied with sewage, public transport and education.

\subsection{URI Indicators in the Three Target Cities}

For deepening our insights of the URI in the three cities, it is necessary to investigate the contribution of each of the 24 indicators to the overall URI. In general, the main contributors can be identified by the indicator's weights presented in Table 1. On average, an indicator's contribution to URI is $100 \%$ divided by 24 , which is $4.2 \%$. In this research, we define that a key indicator to URI is the indicator that has more than $6 \%$ contribution to the overall URI, and a less important indicator is the one that has less than $2 \%$ contribution to the overall URI. Accordingly, the 24 indicators are grouped into (1) 8 key indicators, (2) 9 less important indicators and (3) the remaining 7 in-between indicators. The 8 key indicators and the 9 less important indicators are presented in Table 5 . 
Table 5. URI key contribution indicators and less contribution indicators by weights presented in Table 1.

\begin{tabular}{lll}
\hline \multicolumn{1}{c}{ Key Contribution Indicators } & \multicolumn{1}{c}{ Less Contribution Indicators } \\
\hline (1) Urban citizen's disposable income & $(1)$ & Percentage of population below 14 years old \\
(2) Availability and supply capacity of & $(2)$ & Percentage of population above 65 years old \\
& $(3)$ & Percentage of population with high education \\
water resources & $(4)$ & Urban population density \\
(3) Rate of household waste treatment & $(5)$ Number of mobile phones per 10,000 persons \\
(4) Coverage of medical and health institutions & $(6)$ Health technicians per 10,000 population \\
(5) Proportion of days with good air quality & $(7)$ Proportion of population receiving social assistance \\
(6) Urban green coverage & $(8)$ Public transport for every 10,000 people \\
(7) Emergency response capacity & $(9)$ Road freight density \\
(8) Integrated governance capacity & & \\
& &
\end{tabular}

For the specific cases of the three cities studied, the key contributing indicators and less contributing indicators are recognized by scores of each indicator that is the product of an indicator's weight presented in Table 1 and its real score. Table 6 shows the key contributing indicators and the less contributing indicators for the three cities identified for this research.

As presented in Table 6, all three cities are facing the challenge that the proportion of the population receiving social assistance is low and thus, this indicator contributes less to the URI. This is due to high floating population in the three cities, which results from the Chinese household registration system (the so-called hukou system). This system allows that most social benefits are provided according to people's hukou, and those without a local hukou will not be assisted. As an example, there are 20 million people with Beijing hukou living in Beijing and the low-income group of those people are eligible for receiving social assistance from the municipality of Beijing. However, the reality is that there are 30 million people living and working in Beijing, of which 10 million do not have Beijing hukou and thus, they are non-citizens of Beijing and they are not eligible for enjoying Beijing's social assistance. The same situation exists in most Chinese cities, particularly in Chongqing which is the business center of western China and in Yiwu, where it is a famous international small commodity-producing city.

Table 6. URI key contribution indicators and less contribution indicators of the three target cities in 2018.

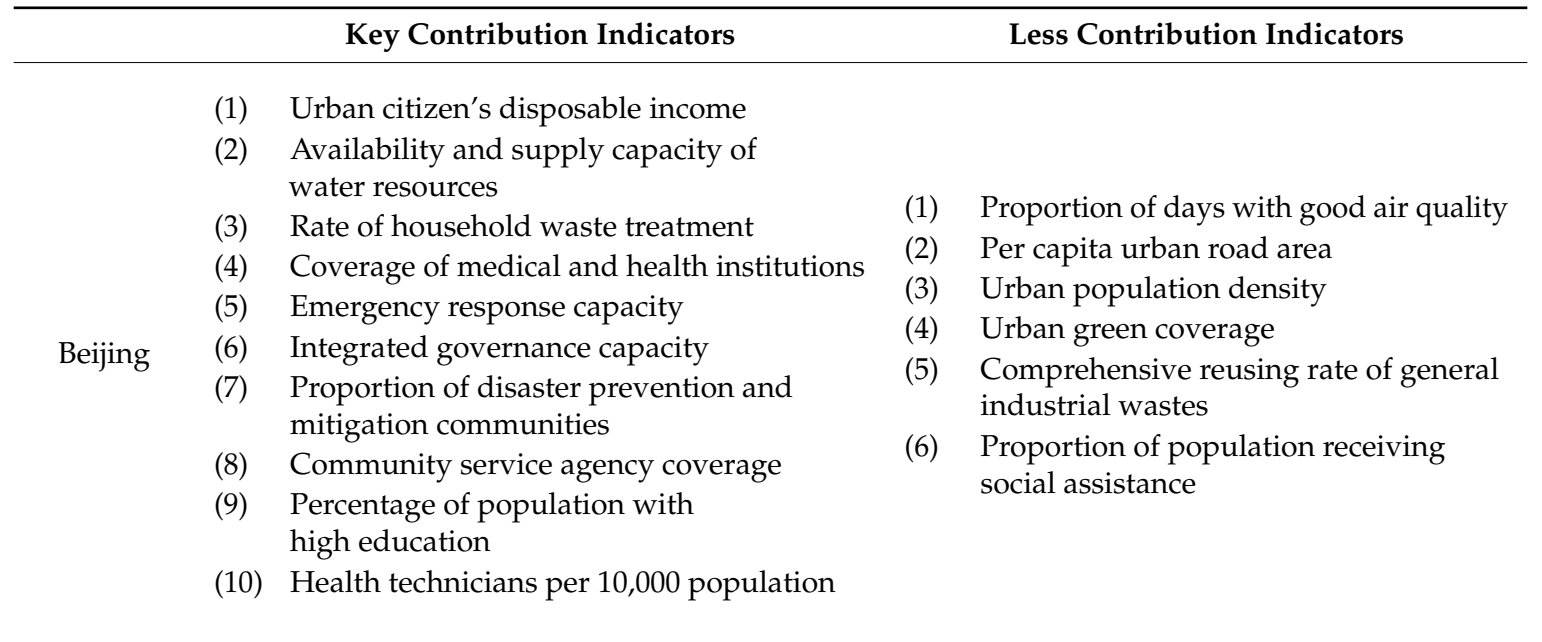


Table 6. Cont.

\begin{tabular}{|c|c|c|c|c|}
\hline & \multicolumn{2}{|r|}{ Key Contribution Indicators } & \multicolumn{2}{|r|}{ Less Contribution Indicators } \\
\hline \multirow{7}{*}{ Chongqing } & & & $(1)$ & Urban citizen's disposable income \\
\hline & & & (2) & Emergency response capacity \\
\hline & (1) & $\begin{array}{l}\text { Availability and supply capacity of } \\
\text { water resources }\end{array}$ & (3) & $\begin{array}{l}\text { Proportion of disaster prevention and } \\
\text { mitigation communities }\end{array}$ \\
\hline & (2) & Proportion of days with good air quality & $(4)$ & Per capita urban road area \\
\hline & (3) & Community service agency coverage & (5) & Urban population density \\
\hline & (4) & $\begin{array}{l}\text { Percentage of population with } \\
\text { high education }\end{array}$ & (6) & $\begin{array}{l}\text { Health technicians per } \\
10,000 \text { population }\end{array}$ \\
\hline & & & (7) & $\begin{array}{l}\text { Proportion of population receiving } \\
\text { social assistance }\end{array}$ \\
\hline
\end{tabular}

(1) Urban citizen's disposable income
(2) Availability and supply capacity of
water resources
(3) Rate of household waste treatment
(4) Proportion of days with good air quality
(5) Emergency response capacity
(6) Integrated governance capacity
(7) Proportion of disaster prevention and
(8) Community service agency coverage
(9) Coverage of medical and health institutions
(10) Percentage of population above 65 years old

(1) Coverage of medical and health institutions

(2) Urban green coverage

(3) Per capita urban road area

(4) Percentage of population with high education

(5) Proportion of population receiving social assistance

(6) Road freight density

\section{Conclusions and Discussions}

Urban resilience to climate change is a complex issue, but measurable. By careful selection and scientific tests, urban resilience to climate change can be effectively measured by an URI. The URI suggested in this research uses data on 24 indicators distributed over six URI component indices. While no measure of such a complex phenomenon can be perfect, the URI proved to be effective, useful and robust.

Notably, the URI ensures access to integrated information on urban resilience to climate change for planners and decision-makers at the city level. It allows a comparison of cities in a systematic manner and this helps to determine in a quantitative way, and enables identification of areas of success or failure and thus, the priorities. It also enables the investigation into interactions between overall URI and various aspects related to urban resilience to climate change.

The URI provides tangible measurement of not only overall indicators of urban resilience to climate change, but also urban resilience components and their related indicators. Therefore, it could meet a wide range of policy and research needs.

The URI creates a linkage between urban resilience to climate change and policy relevance. That is, when a single effort indicated by an individual indicator is made such as improving urban governance, the overall URI response is available. Therefore, it is a useful tool for helping urban decision-makers and urban planners to quantify goals, measure progress, benchmark performance, and identify priorities for achieving high urban resilience to climate change.

The URI builds on an easily understood database using a methodology that is transparent, reproducible, and capable of refinement over time. For 23 of the 24 indicators, data is available from local statistical reports, and no extra costs for data collection have to be made. Only the data on urban governance capacity should be collected through urban satisfaction surveys, which can provide additional and valuable information on citizens' satisfaction of urban performance. The process 
for composing the URI was developed by the Microsoft Excel Program, and thus, it is transparent and reproducible.

The search for an appropriate URI has dominated all kinds of urban resilience assessment programs at the levels of community, city, region, country and the world as a whole. It seems that a single indicator of resilience cannot be defined, and a considerable number of indicators is necessary to capture all dimensions of urban resilience. If too few indicators are monitored, crucially important aspects of urban resilience may escape attention, and if a large number of indicators has to be monitored, there is a potential risk of overlooking essential factors, on the one hand; and, on the other hand, data availability and analysis may become prohibitively expensive and time consuming [30,31]. The task is to create an URI, based upon a number of representative indicators that provide comprehensive information of urban resilience to climate change. The chosen approach for short is: use as many as essential and as small a number of indicators as possible.

China launched an initiative on Urban Adaptation to Climate Change (UACC) in 2016 and all Chinese cities are now facing challenges of both fundamental researches and practices in setting up urban strategies of adaptation to climate change, in which vulnerability, risk assessment, adaptive capacity and resilience building are recognized key elements for Chinese cities in adaptation to climate change. The main approach of the UACC Initiative is learning by doing, since none of the Chinese cities has experience on UACC before 2016 and thus, various tools are called for. Those tools should support learning by doing in the ways that all cities could share knowledge and exchange practices and experiences. URI, as one of those tools, can be used for benchmarking for urban policy- makers, urban planners and all urban practitioners. However, there are flaws in this research. The URI is based on local understanding of urban resilience and it is necessary to ascertain whether this framework can be translated to any other given urban context or whether this framework can truly be adapted to different situations locally, nationally and internationally. Selection of initial indicators and filtering and weighting indicators are mainly applying expert approach and are guided by a participatory approach. It is obvious that expert and stakeholder's participatory approaches are a bit subjective and thus, further testing is needed to judge what are the impacts when different experts and stakeholders are involved.

While no measure of such a complex phenomenon can be perfect, we make the following suggestions for further research in this field. Firstly, it is necessary to operationalize international understanding of urban resilience within local contexts. Local communities are all in different stages of preparedness to adopt and face the challenges of improving urban resilience. They need, locally, to understand urban resilience to climate change, and should have the tools to identify the influence of local governmental policies on local resilience through a process of bottom-up changes. Secondly, a number of refinements for the selection of single indicators and their aggregation need to be undertaken to deepen local understanding of resilience. The score of an URI is highly dependent on what indicators have been used, how many weights have been assigned to the various factors, and what kind of resilience rule has been set up. It is obvious that there are a number of value judgments and there is uncertainty about the causality. It is necessary to go deeper in further studies into these issues. Thirdly, to be useful, the URI suggested by this research needs to be applied in more cities. There are more than 800 cities in China. It is clear that three cities are not enough to represent all the different conditions in urban China. Therefore, it is necessary to extend the URI to more Chinese cities and to modify the URI accordingly. Finally, a major investment in data collection is clearly called for. Both availability and data quality are crucial to a successful measure of urban resilience.

Author Contributions: Conceptualization, M.Z. and M.P.v.D.; methodology, M.Z. and Y.Y.; formal analysis, M.Z. and H.L.; investigation, Y.Y. and H.L.; data curation, Y.Y.; writing-original draft preparation, M.Z.; writing-review and editing, M.P.v.D.; supervision, M.Z. and M.P.v.D.; project administration, M.Z. All authors have read and agreed to the published version of the manuscript.

Funding: This research received no external funding.

Conflicts of Interest: The authors declare no conflict of interest. 


\section{References}

1. Spaans, M.; Waterhourt, B. Building up resilience in cities worldwide - Rotterdam as participant in the 100 Resilient Cities Programme. Cities 2017, 61, 109-116. [CrossRef]

2. Van Dijk, M.P.; Mingshun, Z. Paradigms in urban water management in China. Sustainability 2019, 11, 3001. [CrossRef]

3. Birkmann, J.; Welle, T.; Krause, D.; Wolfertz, J.; Suarez, D.; Setiadi, N. World risk index: Concept and results. In WorldRiskReport; Alliance Development Works: Berlin, Germany, 2011; pp. 13-43.

4. Birkmann, J.; Welle, T. The World Risk Index 2016: Reveals the necessity for regional cooperation in vulnerability reduction. J. Extrem. Events 2016, 3, 1650005. [CrossRef]

5. Welle Tand Birkmann, J. The World Risk Index-An approach to assess risk and vulnerability on a global scale. J. Extrem. Events 2015, 2, 34. [CrossRef]

6. Queiroz de Almeida, L.; Welle, T.; Birkmann, J. Disaster risk indicators in Brazil: A proposal based on the worldriskindex. Int. J. Disaster Risk Reduct. 2016, 17, 251-272. [CrossRef]

7. Manyena, S.B. The Concept of Resilience Revisited. Disasters 2006, 30, 434-450. [CrossRef]

8. Cutter, S.L.; Barnes, L.; Berry, M.; Burton, C.; Evans, E.; Tate, E.; Webb, J. A Place-Based Model for Understanding Community Resilience to Natural Disasters. Glob. Environ. Chang. 2008, 18, 598-606. [CrossRef]

9. Simpson, D.M. Indicator Issues and Proposed Framework for a Disaster Preparedness Index (DPI); Draft report Version 1.0; Center for Hazards Research and Policy Development, University of Louisville: Louisville, KY, USA, 2006.

10. Kusumastuti, R.D.; Husodo, Z.A.; Suardi, L.; Danarsari, D.N. Developing a Resilience Index towards Natural Disasters in Indonesia. Int. J. Disaster Risk Reduct. 2014, 10 Pt A, 327-340. [CrossRef]

11. Blackmore, J.M.; Plant, R.J. Risk and Resilience to Enhance Sustainability with Application to Urban Water Systems. J. Water Resour. Plan. Manag. 2008, 134, 224-233. [CrossRef]

12. Suárez, M.; Gómez-Baggethun, E.; Benayas, J.; Tilbury, D. Towards an Urban Resilience Index: A Case Study in 50 Spanish Cities. Sustainability 2016, 8, 774.

13. Joerin, J.; Shaw, R.; Takeuchi, Y.; Krishnamurthy, R. The Adoption of a Climate Disaster Resilience Index in Chennai, India. Disasters 2014, 38, 540-561. [CrossRef] [PubMed]

14. Kim, D.; Lim, U. Urban Resilience in Climate Change Adaptation: A Conceptual Framework. Sustainability 2016, 8, 405. [CrossRef]

15. Qihui, X. The inspiring policies on construction of resilience cities in developed world. Sci. Decis. Mak. 2017, 4, 60-75.

16. The Rockefeller Foundation and ARUP. City Resilience Framework; The Rockefeller Foundation and ARUP: New York, NY, USA, 2014; Available online: https://www.arup.com/projects/city-resilience-index (accessed on 16 October 2020).

17. Klein, R.J.T.; Nicholls, R.J.; Thomalla, F. Resilience to Natural Hazards: How Useful is This Concept? Glob. Environ. Chang. Part B Environ. Hazards 2003, 5, 35-45. [CrossRef]

18. Carpenter, S.R.; Arrow, K.J.; Barrett, S.; Biggs, R.; Brock, W.A.; Crépin, A.S.; Engström, G.; Folke, C.; Hughes, T.P.; Kautsky, N.; et al. General Resilience to Cope with Extreme Events. Sustainability 2012, 4 , 3248-3259. [CrossRef]

19. Sharifi, A.; Yamagata, Y.A. Conceptual Framework for Assessment of Urban Energy Resilience. Energy Procedia 2015, 75, 2904-2909. [CrossRef]

20. Milman, A.; Short, A. Incorporating Resilience into Sustainability Indicators: An Example for the Urban Water Sector. Glob. Environ. Chang. 2008, 18, 758-767. [CrossRef]

21. Mugume, S.N.; Gomez, D.E.; Fu, G.; Farmani, R.; Butler, D. A Global Analysis Approach for Investigating Structural Resilience in Urban Drainage Systems. Water Res. 2015, 81, 15-26. [CrossRef]

22. Feldmeyer, D.; Wilden, D.; Jamshed, A.; Birkmann, J. Regional climate resilience index: A novel multimethod comparative approach for indicator development, empirical validation and implementation. Ecol. Indic. 2020, 119, 106861. [CrossRef]

23. Van Dijk, M.P. Shifts in urban water governance paradigms. Int. J. Water 2012, 6, 137-155. 
24. IPCC. Climate change 2014: Impacts, adaptation, and vulnerability. In Working Group II Contribution to the Fifth Assessment Report of the Intergovernmental Panel on Climate Change; Cambridge University Press: Cambridge, UK; New York, NY, USA, 2014.

25. Bozza, A.; Asprone, D.; Manfredi, G. Developing an Integrated Framework to Quantify Resilience of Urban Systems Against Disasters. Nat. Hazards 2015, 78, 1729-1748. [CrossRef]

26. Cutter, S.L.; Burton, C.G.; Emrich, C.T. Disaster Resilience Indicators for Benchmarking Baseline Conditions. J. Homel. Secur. Emerg. Manag. 2010, 7, 1271-1283. [CrossRef]

27. Shaw, R.; Team, I.E.D.M. Climate Disaster Resilience: Focus on Coastal Urban Cities in Asia. Asian J. Environ. Disaster Manag. 2009, 1, 101-116.

28. Yiwen, S.; Jiang, X. Conceptual analysis on international literature reviews of urban resilience. Int. Urban Plan 2015, 2, 48-54.

29. Van Dijk, M.P.; Mingshun, Z. Sustainability indices as a tool for urban managers, evidence form four medium-sized Chinese cities. Environ. Impact Assess. Rev. 2005, 25, 667-688. [CrossRef]

30. Mingshun, Z.; Zelu, L.; Van Dijk, M.P. Measuring urban vulnerability to climate change using an integrated approach, assessing climate risks in Beijing. PeerJ 2019, 7, e7018. [CrossRef]

31. Mingshun, Z.; Huan, W.; Wei, J.; Van Dijk, M.P. Assessing heat wave vulnerability in Beijing and its districts, using a three dimensional model. Int. J. Glob. Warm. 2019, 17, 297-314. [CrossRef]

Publisher's Note: MDPI stays neutral with regard to jurisdictional claims in published maps and institutional affiliations. 